\title{
Clinicopathological Study of Gastric Carcinoma with Special Reference to Helicobacter pylori
}

\author{
Jimmy Narayan ${ }^{1}$ (D) , Ayaskanta Singh ${ }^{1 *}$ (D) , Bimala Mishra², Niranjan Rout ${ }^{3}$, \\ Rabi Narayan Mallick², A.K. Mohanty ${ }^{2}$ and Shivaram Prasad Singh ${ }^{4}$ (D)
}

${ }^{1}$ Department of Gastroenterology, IMS and SUM Hospital, Siksha O Anusandhan, Deemed to be University, Bhubaneswar, Odisha, India. ${ }^{2}$ Department of Pathology, S.C.B. Medical College, Cuttack, Odisha, India. ${ }^{3}$ Department of Onco-Pathology, Acharya Harihar Regional Cancer Center, Cuttack, Odisha, India. ${ }^{4}$ Department of Gastroenterology, S.C.B. Medical College, Cuttack, Odisha, India.

\begin{abstract}
Gastric cancer (GC) is one of the most common malignancies. Although Helicobacter pylori (H. pylori) is being recognized as a Type I carcinogen for GC and primary gastric lymphoma (PGL), yet many studies especially from the Indian subcontinent do not show any such association. The aim of the study was to evaluate the clinicopathological characteristics of gastric adenocarcinoma and to determine the association of $\boldsymbol{H}$. pylori infection. This prospective study included $\mathbf{5 0}$ cases of histologically proven gastric adenocarcinoma. A detailed clinical history, physical examination and upper gastrointestinal endoscopy were done in all the cases and mucosal biopsies were taken from the growth and the surrounding mucosa. Rapid urease test (RUT) was done to diagnose $H$. pylori infection. 50 patients of functional dyspepsia were taken as controls. GC was more common in males $(70 \%)$. The maximum cases were recorded in elderly persons, mostly from $5^{\text {th }}$ to $6^{\text {th }}$ decades. Anorexia $(60 \%)$, dyspepsia (54\%) and weight loss $(24 \%)$ were the commonest clinical presentation. Most of the patients presented within 3-12 month of onset of symptom. In majority of cases, the lesion was confined to the antrum (62\%) and body (26\%) of the stomach. H. pylori infection was more commonly isolated from the antrum. H. pylori infection was not significantly associated with GC as compared to patients with functional dyspepsia. No association was found between $\mathrm{H}$. pylori infection and gastric carcinoma. Probably gastric cancer is multifactorial disease where dietary, genetic and environmental factors play contributing roles.
\end{abstract}

Keywords: Gastric Neoplasm, India, Helicobacter pylori.

*Correspondence: ayaskant1ce@gmail.com; 9437155625

(Received: 02 July 2019; accepted: 18 October 2019)

Citation: Jimmy Narayan, Ayaskanta Singh, Bimala Mishra, Niranjan Rout, Rabi Narayan Mallick, A.K. Mohantyand Shivaram Prasad Singh, Clinicopathological Study of Gastric Carcinoma with Special Reference to Helicobacter pylori, J Pure App/ Microbiol., 2019, 13(4):2021-2025. https://doi.org/10.22207/JPAM.13.4.13

(C) The Author(s) 2019. Open Access. This article is distributed under the terms of the Creative Commons Attribution 4.0 International License which permits unrestricted use, sharing, distribution, and reproduction in any medium, provided you give appropriate credit to the original author(s) and the source, provide a link to the Creative Commons license, and indicate if changes were made. 


\section{INTRODUCTION}

Gastric cancer (GC) is one of the most common malignancies, not only in Asia but also worldwide ${ }^{1}$. It ranks second among males and third among females as the commonest malignancy in the world ${ }^{1}$. Most of the gastric cancer patients present in advanced stages and the five-year survival are less than $20 \%$ in developing countries like India ${ }^{2}$. International Agency for Research on Cancer has recognized Helicobacter Pylori $(H$ pylori) as a Type I carcinogen for gastric cancer (GC) and primary gastric lymphoma (PGL), way back in $1994^{3}$. Meta-Analyses and various epidemiological studies have revealed a strong relationship between $\mathrm{H}$ pylori and $\mathrm{GC}$ and $\mathrm{PGL} \mathrm{L}^{4,5}$.

H. pylori infection colonizes the mucosal lining of the gastrointestinal tract, mainly the stomach and duodenum. It causes chronic active gastritis in almost all cases ${ }^{6}$. As the infection is rarely self-limiting, it initiates a sequence of inflammatory-mediated changes, within the gastric epithelium. It is seen that over a period of decades, there occur degenerative changes which later evolves into the well-established precancerous conditions such as atrophic gastritis, metaplasia, and dysplasia ${ }^{6}$.

There has been a paradoxical observation of high prevalence of $H$. pylori infection and low GC rates, in some geographical region like Africa and India" ${ }^{7-9}$. The authors have used terms like "African Enigma" and "Indian Enigma" of H. pylori infection and $\mathrm{GCs}^{8,9}$. It has been observed that etiological factors, other than $H$. pylori infection, are also involved in gastric carcinogenesis, such as dietary and host genetic factors.

The aim of the study was to study the clinicopathological types of gastric malignancies with special reference to $H$. pylori infection.

\section{MATERIAL AND METHODS}

The present study was conducted in the department of pathology and gastroenterology of S.C.B. Medical College, Cuttack, Odisha from January 2004 to January 2005. A total number of 50 consecutive cases of gastric adenocarcinoma, which were suspected on endoscopy and later proven histologically, were included in this study. A detailed clinical history was taken and physical examination was done in all the cases. The mucosal biopsies were taken from the growth and the normal surrounding region. At endoscopy, the site, extent, appearance and mucosal friability of the suspected lesions were noted. Additional biopsy bits were taken from the growth and also the normal surrounding areas to test for $\mathrm{H}$. pylori . Rapid urease test (RUT) was done to look for $\mathrm{H}$ pylori infection. All the tissue samples were processed and stained with routine haematoxyline and eosin (HE) stain and special stain, i.e the giemsa stain. Another 50 patients of functional dyspepsia who had apparently normal mucosal studies were tested for $\mathrm{H}$. pylori using RUT. All values are presented in mean and percentage, chi square test was used to test association using SPSS software. P value $<0.05$ was considered to be statistically significant.

\section{Observation}

In this study, all the patients were in the age range of 20-80 years. The maximum number of cases were found within the age range of $5^{\text {th }}$ $\& 6^{\text {th }}$ decades $(54 \%)$. Males $(70 \%)$ were seen more commonly affected than females (30\%) and Gender (Male to Female) ratio was found to be 2.3:1 [Table1].

Table 1. Age and Sex Distribution of Cases studied)

\begin{tabular}{|c|c|c|c|c|c|c|}
\hline \multirow{2}{*}{$\begin{array}{l}\text { Age gr. } \\
\text { In years }\end{array}$} & \multicolumn{2}{|c|}{ Male } & \multicolumn{2}{|c|}{ Female } & \multicolumn{2}{|l|}{ Total } \\
\hline & No. & $\%$ & No. & $\%$ & No. & $\%$ \\
\hline $21-30$ & 1 & 2 & 2 & 4 & 3 & 6 \\
\hline $31-40$ & 3 & 6 & 3 & 6 & 6 & 12 \\
\hline $41-50$ & 7 & 14 & 6 & 12 & 13 & 26 \\
\hline $51-60$ & 13 & 26 & 1 & 2 & 14 & 28 \\
\hline $61-70$ & 6 & 12 & 3 & 6 & 9 & 18 \\
\hline $71-80$ & 5 & 10 & 0 & 0 & 5 & 10 \\
\hline Total & 35 & 70 & 15 & 30 & 50 & 100 \\
\hline
\end{tabular}

In this study, the most common symptoms of GC patients were anorexia (60\%) and dyspepsia $(54 \%)$ [Table 2]. The other symptoms were vomiting (34\%), abdominal pain (32\%), melena $(30 \%)$, nausea $(26 \%)$, weight loss $(26 \%)$ and haematemesis $(16 \%)$. The maximum number of cases were reported within 3-12 months of onset of symptoms.

Endoscopic observation showed antrum $(62 \%)$ to be the most common site of involvement, followed by body or corpus (26\%), fundus (6\%) and G.E. Junction (6\%). Only the malignant growths at the pyloric antrum and body showed positive results for $H$. pylori inflammation. The growth at 
Table 2. Clinical Presentation of Gastric Carcinoma

\begin{tabular}{lcc}
\hline $\begin{array}{l}\text { Presenting } \\
\text { Symptoms }\end{array}$ & $\begin{array}{c}\text { Number } \\
(\mathrm{n})\end{array}$ & $\begin{array}{c}\text { Percentage } \\
(\%)\end{array}$ \\
\hline Anorexia & 30 & 60 \\
Dyspepsia & 27 & 54 \\
Vomiting & 17 & 34 \\
Abdominal pain & 16 & 32 \\
Weight Loss & 13 & 26 \\
Melena & 15 & 30 \\
Hematemesis & 8 & 16 \\
\hline
\end{tabular}

other sites did not reveal any $H$. pylori in the tissue section [Table 3].

Endoscopically ulcerated lesion (66\%) was found to be most common type followed by fungating $(16 \%)$, nodular $(14 \%)$ and ulcero infiltrative type (4\%). Histological examination showed that diffuse patterns (68\%) were predominant over intestinal type (32\%) of adenocarcinoma. Out of all cases, only 12 (24\%) cases were $H$. pylori positive and the rest did not show any evidence of organisms. The incidence of $H$. pylori in intestinal type adenocarcinoma (31.25\%) was slightly higher than diffuse type (20.5\%) [Table 4]. Only 9 cases out of 35 males

Table 3. Site of growth and incidence of $H$. pylori to site of Growth

\begin{tabular}{lccccc}
\hline $\begin{array}{l}\text { Site of } \\
\text { growth }\end{array}$ & \multicolumn{2}{c}{$\begin{array}{c}\text { Total No. of } \\
\text { cases }\end{array}$} & & \multicolumn{2}{c}{$\begin{array}{c}\text { H. pylori } \\
(+)\end{array}$} \\
\cline { 2 - 3 } \cline { 5 - 6 } \cline { 5 - 6 } & $\%$ & No. & & No. & $\%$ \\
\hline GE Junction & 3 & 6 & & 0 & 0 \\
Fundus & 3 & 6 & & 0 & 0 \\
Body & 13 & 26 & & 3 & 23.7 \\
Pylori antrum & 31 & 62 & & 9 & 29.8 \\
\hline
\end{tabular}

Table 4. Incidence of $H$. Pylori according to site of Growth

\begin{tabular}{|c|c|c|c|c|}
\hline \multirow[t]{2}{*}{$\begin{array}{l}\text { Histological } \\
\text { Types }\end{array}$} & \multicolumn{2}{|c|}{$\begin{array}{c}\text { Total No. of } \\
\text { cases }\end{array}$} & \multicolumn{2}{|c|}{ H. pylori } \\
\hline & No. & $\%$ & No. & $\%$ \\
\hline Diffuse type & 34 & 68 & 7 & 28.5 \\
\hline Intestinal type & 16 & 32 & 5 & 31.25 \\
\hline Total & 50 & 100 & 12 & 24 \\
\hline
\end{tabular}

$\mathrm{p}=0.485(>0.05)$
(25.7\%) and 3 cases out of 15 females (20\%) were H. pylori positive. However, RUT was positive in 56 $\%$ of controls, which was statistically higher than the malignant cases [Table 5].

Table 5. $H$ pylori infection in cases vs controls

\begin{tabular}{lccc}
\hline & $\begin{array}{c}\text { Cancer } \\
\text { present }\end{array}$ & $\begin{array}{c}\text { Cancer } \\
\text { absent }\end{array}$ & $\begin{array}{c}\mathrm{p} \\
\text { value }\end{array}$ \\
\hline H. pylori present & 12 & 28 & $<0.05$ \\
H. pylori absent & 38 & 22 & \\
\hline
\end{tabular}

\section{DISCUSSION}

The result of the study as regards to age incidence of patients was compatible with a study performed in southern India, where it was observed that the maximum number of cases were beyond the age of 50 years ${ }^{10}$. In this study, significant male predisposition was seen with male to female ratio 2.3:1. This was similar to the studies by Parkin et al. and Sumathi et al., in which it was noted that the cancer was twice as common in males as compared to females ${ }^{10,11}$.

In this present series, the most common symptoms were anorexia, weight loss and gastro intestinal bleed which is similar to other studies done from India ${ }^{12,13}$. The most common site of involvement of GC was antrum (62\%), followed by body (26\%) fundus (6\%) and gastro esophageal junction (6\%), The study by Marson et al. also found that distal (antral) carcinoma was more common in comparison to cardia ${ }^{14}$. However, there has been a trend in the increase of proximal gastric carcinomas especially those involving the cardia in recent years as compared to distal sites ${ }^{15}$. Majority (> $95 \%$ ) of GCs are adenocarcinoma. They are further divided into intestinal and diffuse types. It is seen that the intestinal pattern is more common than diffuse pattern and mixed pattern ${ }^{15}$. However, the present study shows that the diffuse type (68\%) is more common than the intestinal (32\%) type. Some authors have postulated that intestinal type of adenocarcinoma was prominent in high risk geographical regions and it was less commonly found in low risk region ${ }^{16}$. As India belongs to the low prevalence region of gastric carcinoma, this might be the cause of low incidence of intestinal type of gastric adenocarcinoma in the present study. 
In this present study, the incidence of H. pylori positivity in GC patients was only $24 \%$, which was significantly less than the control group. Although $H$. pylori is being recognized as a causative agent for GC, yet the few case control studies published from India unexpectedly fail to show an association between $H$. pylori infection and GC. Kate et al. performed a case control study where 50 patients with gastric neoplasms and 50 controls with non-ulcer dyspepsia (NUD) were enrolled. They found that $H$. pylori infection was detected less commonly in GC $(38 \%)$ than those with NUD $(68 \%)^{17}$. Another study from South India showed that $64.7 \%$ of patients with gastric adenocarcinoma and $74.4 \%$ of patients with NUD tested positive for H. pylori ${ }^{18}$. Another case control study from Lucknow had taken a better sample size of 279 cases with gastric neoplasms ( $263 \mathrm{GCs}$ and $16 \mathrm{GLs}$ ) and 456 healthy controls. This study also failed to demonstrate that $H$. pylori infection was more common in patients with gastric neoplasm as compared to the controls ${ }^{19}$. The authors have postulated a few reasons for such a low prevalence of $\mathrm{H}$ pylori in $\mathrm{GC}$ patients in India. All these studies have used gastroscopy based rapid urease tests (RUT) to diagnose H. pylori infection. The problem with these endoscopy-based tests is that in patients with GC due to the presence of underlying gastric atrophy and intestinal metaplasia, the tests can be false negative. A combination of methods (RUT and serology) improved the detection of $H$. pylori infection in comparison to a single method. It is postulated that in a country like India, etiological factors (such as diet, addictions, host genetic factors) other than $\mathrm{H}$. pylori infection might be the cause of gastric carcinoma ${ }^{10,14}$.

The landmark paper by Parsonet et al on the $H$. pylori association with GC has shown that distal GC had higher incidence of $H$. pylori infection as compared to proximal GC (especially of gastric cardia and GE junction). The present paper also showed a similar observation. Another interesting finding was that the prevalence of $H$. pylori in the intestinal type was slightly higher than the diffuse type, although the study by Parsonet et. al observed that both diffuse and intestinal type have an almost equal association with $H$. pylori infection.

\section{Limitation of the study}

There are a few limitations of the study. RUT only was used to diagnose $H$. pylori infection, which can be false negative in a few cases of gastric atrophy. Serology would have been better. The other risk factors such as diet and genetic factors were not studied in the present paper.

\section{CONCLUSION}

Gastric carcinoma was more common in males. The maximum cases were recorded in elderly persons, mostly in $5^{\text {th }}$ to $6^{\text {th }}$ decades. Anorexia, dyspepsia and weight loss were the dominant clinical presentation and most of the patients presented within 3-12 months of onset of symptoms. In majority of cases, malignant lesion was confined to the antrum and body of the stomach and $H$. pylori was more commonly isolated from the antrum. The diffuse pattern of adeno carcinoma is more common than the intestinal type of adenocarcinoma in the stomach. H. pylori infection was not significantly associated with GC as compared to patients with functional dyspepsia. GC is probably a multi factorial disease where genetic, dietary and environmental factors and $H$. pylori together play an important role in the pathogenesis.

\section{ACKNOWLEDGEMENTS}

Not applicable.

\section{CONFLICT OF INTEREST}

The authors declares that there is no conflict of interest.

\section{AUTHORS' CONTRIBUTIONS}

All authors listed have made a substantial, direct and intellectual contribution to the work, and approved it for publication.

\section{FUNDING}

None.

\section{DATA AVAILABILITY}

All datasets generated or analyzed during this study are included in the manuscript and/or the Supplementary Files. 


\section{ETHICS STATEMENT}

This article does not contain any studies with human participants or animals performed by any of the authors.

\section{REFERENCES}

1. Ferlay J, Shin HR, Bray F, Forman D, Mathers C, Parkin DM. Peter Boyle, Bernard Levin., editors. GLOBOCAN 2008, Cancer Incidence and Mortality Worldwide: IARC CancerBase No. 10. Lyon, France: International Agency for Research on Cancer, 2010. Available from: http:// www.globocan.iarc.fr. World Cancer Report, 2008 IARC; 2008

2. Mohandas KM, Jagannath P. Epidemiology of digestive tract cancers in India. VI. Projected burden in the new millennium and the need for primary prevention. Indian J. Gastroenterol., 2000; 19: 74-8.

3. Schistosomes, liver flukes and Helicobacter pylori. IARC Working Group on the Evaluation of Carcinogenic Risks to Humans. Lyon, 7-14 June 1994. IARC Monogr. Eval. Carcinog Risks Hum., 1994; 61: 1-241.

4. Xue FB, Xu YY, Wan Y, Pan BR, Ren J, Fan DM. Association of $H$. pylori infection with gastric carcinoma: a Meta analysis. World J. Gastroenterol., 2001; 7: 801-804. https://doi.org/10.3748/wjg.v7.i6.801

5. Eslick GD, Lim LL, Byles JE, Xia HH, Talley NJ. Association of Helicobacter pylori infection with gastric carcinoma: a metaanalysis. Am J. Gastroenterol., 1999; 94: 23732379.

6. Go MF. Natural history and epidemiology of Helicobacter pylori infection. Alimentary pharmacology \& therapeutics, 2002; 16: 3-15. https://doi. org/10.1046/j.1365-2036.2002.0160s1003.x

7. Miwa H, Go MF, Sato N. H pylori and gastric cancer: the Asian enigma. Am. J. Gastroenterol., 2002; 97: 1106-1112.

8. Lunet N, Barros H. Helicobacter pylori infection and gastric cancer: facing the enigmas. Int. J. Cancer, 2003; 106: 953-960. https://doi.org/10.1002/ijc.11306

9. Holcombe C. Helicobacter pylori: The African Enigma. Gut., 1992; 33: 429-431. https://doi.org/10.1136/ gut.33.4.429
10. Sumathi B, Ramalingam S, Navaneethan U, Jayanthi V. Risk factors for gastric cancer in South India. Singapore Medical Journal, 2009; 50(2): 147.

11. Parkin DM, Muir CS Whelan SL, Gao YI, Freday J, Cancer incidence in Five continents volume VI-, International Agency for Reserch on cancer, Scientific publication No. 120, Lyon: IARC, 1992.

12. Dikshit RP, Mathur G, Mhatre S, Yeole BB. Epidemiological review of gastric cancer in India. Indian journal of medical and paediatric oncology: official journal of Indian Society of Medical \& Paediatric Oncology, 2011; 32(1):3. https://doi. org/10.4103/0971-5851.81883

13. Sharma A, Radhakrishnan V. Gastric cancer in India. Indian journal of medical and paediatric oncology: official journal of Indian Society of Medical \& Paediatric Oncology. 2011; 32(1): 12. https://doi. org/10.4103/0971-5851.81884

14. Pavithran K, Doval DC, Pandey KK. Gastric cancer in India. Gastric Cancer. 2002 Dec 20;5(4):0240-3. https:// doi.org/10.1007/s101200200042

15. Lauren P. The two histological main types of gastric carcinoma: diffuse and so called intestinal type carcinoma: an attempt at a histo clinical classification. Acta Pathologica Microbiologica Scandinavica. 1965; 64(1): 31-49. https://doi.org/10.1111/ apm.1965.64.1.31

16. Coraanem, ME, Dekker, W. Block, P et.al time trends in gastric cancer, changing pattern of type and location. Am J. Gastroenterol., 1992, 87: 572.

17. Kate V et al. H. pylori and gastric carcinoma: evidence for the link. Natl. Med. J. India., 2000; 13: 329.

18. Khanna AK, Seth P, Nath G, Dixit VK, Kumar M. Correlation of $H$. pylori and gastric carcinoma. J. Postgrad. Med., 2002; 48: 27-28.

19. Ghoshal UC et al. Frequency of $H$. pylori and CagA antibody in patients with gastric neoplasms and controls: The Indian enigma. Am. J. Gastroenterol. 2005; 100: S64. https://doi.org/10.14309/00000434200509001-00122

20. Parsonnet J, Friedman GD, Vandersteen DP, Chang Y, Vogelman JH, Orentreich N, Sibley RK. Helicobacter pylori infection and the risk of gastric carcinoma. New England Journal of Medicine, 1991; 325(16): 1127-31. https://doi.org/10.1056/NEJM199110173251603 